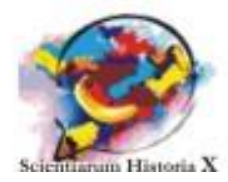

\title{
Colorindo o ensino de química: o efeito da cor no aprendizado de Química
}

\section{Coloring chemistry teaching: the effect of color on chemistry learning}

Ariana L. Maia

Instituto de Química, Universidade Federal do Rio de Janeiro.

arianaliporace@gmail.com

orcid.org/0000-0002-36304765

\section{Priscila Tamiasso-Martinhon}

Instituto de Química, Universidade Federal do Rio de Janeiro.

Núcleo de Estudos em Biomassa e Gerenciamento de Águas-NAB, Universidade

Federal Fluminense.

Grupo Interdisciplinar de Educação, Eletroquímica, Saúde, Ambiente e Arte

(GIEESAA).

pris-martinhon@hotmail.com

orcid.org/0000-0001-6141-3755

\section{Angela S. Rocha}

Instituto de Química, Universidade do Estado do Rio de Janeiro.

Núcleo de Estudos em Biomassa e Gerenciamento de Águas-NAB, Universidade

Federal Fluminense.

Grupo Interdisciplinar de Educação, Eletroquímica, Saúde, Ambiente e Arte

(GIEESAA).

angela.sanches.rocha@gmail.com

orcid.org/0000-0002-3575-4844

\section{Célia Sousa}

Instituto de Química, Universidade Federal do Rio de Janeiro.

Núcleo de Estudos em Biomassa e Gerenciamento de Águas-NAB, Universidade

Federal Fluminense.

Grupo Interdisciplinar de Educação, Eletroquímica, Saúde, Ambiente e Arte

(GIEESAA).

sousa@iq.ufrj.br

orcid.org/0000-0001-8988-3724 
Resumo. As ciências exatas são interpretadas por muitos como sendo distantes do saber cotidiano e difíceis de serem compreendidas. Mas, e se os conhecimentos relacionados a elas fossem passados de outro modo? Se o ensino tivesse como principal foco os aspectos que comumente despertam o interesse das pessoas? Dentro dessa perspectiva, a temática cor pode ser adotada como instrumento criativo para o aprendizado de química. $\mathrm{O}$ objetivo deste trabalho é mostrar como o efeito das cores na química pode ser um aliado no aprendizado desta área das ciências exatas, estimulando o interesse dos alunos e, consequentemente facilitando o processo de ensino e aprendizagem.

Palavras-chave: Cor, Química, Aprendizado.

\begin{abstract}
The exact sciences are interpreted by many people, as being distant from everyday knowledge and difficult to understand. But, what would it be like if knowledge were worked on in another way? If teaching was focused mainly on the aspects that commonly arouse people's interest? In perspective, the color theme could be adopted as a creative instrument for chemistry learning. The objective of this work is to show how the effect of colors on chemistry can be an ally in learning this area of the exact sciences, stimulating the interest of students and, consequently facilitating the teaching and learning process.
\end{abstract}

Keywords: Color, Chemistry, Learning.

Recebido: 01/10/2017 Aceito: 27/10/2017 Publicado: 05/11/2017

\title{
1. Introduçãa
}

A cor pode ser definida como sendo a propriedade de uma radiação eletromagnética, com comprimento de onda pertencente ao espectro visível, capaz de produzir no olho, uma sensação característica (LONDERO, 2016; DENIS, 2009, p.12).

Para o entendimento completo das cores, é preciso compreender, antes de mais nada, o que é luz. A luz são ondas eletromagnéticas com propriedades que dependem da faixa de comprimento de onda que apresentam e se propagam através dos diferentes materiais. Desta forma, as ondas eletromagnéticas possuem duas características que a descrevem: a frequência e o comprimento de onda. $\mathrm{O}$ conjunto de ondas eletromagnéticas que compreendem todas as faixas de comprimentos de onda observados na natureza definem o que chamamos de espectro eletromagnético (LUZZI, 2017; NETO, 2007; UFF, s.n.).

A luz visível ou o espectro visível, é uma parte do espectro eletromagnético cujos comprimentos de onda são identificados como cores pelos nossos olhos, sendo cada cor referente a uma faixa estreita de comprimento de onda específico. Então, os olhos humanos são capazes de detectar apenas a luz visível, não enxergando por exemplo a radiação ultravioleta e a infravermelha, que são muito nocivas para nosso organismo. $\mathrm{O}$ espectro visível inicia-se no vermelho, com comprimento de onda em torno de $700 \mathrm{~nm}$ e 
termina no violeta, cujo comprimento de onda característico está em torno de $400 \mathrm{~nm}$ (MARTINS et al., 2015).

Neste trabalho, são apresentados e discutidos como o uso de transformações químicas, envolvendo mudanças de coloração, são potencialmente interessantes para facilitar o ensino de química de uma forma criativa e atraente para os alunos.

\section{A cor como instrumento de medida}

A visão pode ser considerada o sentido mais utilizado pela espécie humana, por proporcionar a absorção de uma grande quantidade de informações em um intervalo muito curto de tempo, além do que, é através desse sentido que a maioria dos seres humanos analisa inicialmente o ambiente no qual está inserido (KANASHIRO, 2003). O olho, além de possibilitar a análise do ambiente mesmo que de longe, permite discriminar os objetos quanto a suas formas, se estão perto ou longe, se estão em movimento e, em alguns casos, se são coloridos. Além da construção visual sobre o ambiente onde se encontram, as imagens são utilizadas como elementos de comunicação (NISHIDA, 2012).

É através da visão que somos capazes de enxergar as cores e, das muitas informações trazidas pelos nossos olhos, a cor tem um efeito especial. Ela é capaz de provocar várias sensações, dentre elas podemos destacar a curiosidade e a imaginação, que são essenciais quando vamos aprender algo (LORETO e SARTORI, 2008). A cor e a química andam quase sempre juntas. Portanto a cor por despertar o interesse e manter nossa atenção, se torna um instrumento criativo, mutável e eficiente no aprendizado de química.

\section{A cor na química}

Na química, não é difícil cruzarmos com as cores, isto é, encontrarmos sistemas com coloração típica que os nossos olhos são capazes de observar, vários compostos químicos são coloridos de modo que é possível verificar que uma reação química está ocorrendo por meio de mudança de coloração do meio reacional.

Essas reações em que ocorrem mudanças de coloração podem ser utilizadas para elucidar e facilitar a compreensão de inúmeros conceitos químicos. Por exemplo, a mudança de cor pode indicar o ponto de neutralização em titulações ácido-bases nas quais se usa indicadores que mudam de coloração quando o $\mathrm{pH}$ do meio é alterado. Também pode caracterizar o estado de oxidação de um determinado elemento presente em uma substância, ou mesmo seu grau de hidratação, por exemplo o sulfato de $\mathrm{Cu}$ (II), sulfato cúprico, quando anidro tem coloração branca ou cinzenta, mas é um sal muito solúvel e, na forma hidratada apresenta coloração azul intensa.

A estrutura cristalina dos materiais também pode ser avaliada por meio de coloração, o carbono na forma de diamante é incolor, mas como grafite é escuro e opaco. Impurezas também conferem coloração a substâncias, o que é comum nas pedras preciosas e 
semipreciosas. É possível obter informações sobre solubilidade, equilíbrio químico, cinética de reação e muitas outras informações com o uso de sistemas coloridos.

As reações oscilantes são um exemplo de reações químicas nas quais podemos observar mudança de cor repetidas vezes em um curto intervalo de tempo. Apesar da pratica dessas reações no ensino de química não ser comum, elas são extremamente atraentes e interessantes quimicamente, pois as reações ocorrem num sentido e depois no outro sentido, sem que se tenha alterado nenhum parâmetro da reação, e se isto ocorrer com mudança de coloração, torna-se fácil detectar as mudanças reacionais, causando expectativa nos alunos que observam as transformações e, consequentemente despertando seu interesse.

Na reação de Briggs-Rauscher, por exemplo, a mudança de coloração é consequência das reações de oxidação e redução que ocorrem no sistema reacional, de modo que são misturadas soluções incolores, que se tornam âmbar, depois azul e depois incolor novamente, sendo que estas mudanças ocorrem sucessivamente várias vezes em intervalos que aumentam até se tornar azul em definitivo.

Acredita-se que, por meio destas reações podemos explorar conceitos de número de oxidação, agentes oxidantes e redutores, estequiometria de reações redox, velocidade de reação e fatores que a influenciam, equilíbrio químico entre outros. $\mathrm{O}$ apelo visual é grande e espera-se de fato que os alunos fiquem interessados no fenômeno que está ocorrendo e assim queiram entender o que está ocorrendo e porque, sendo um mecanismo de quebra da barreira que comumente se forma entre professor e aluno, facilitando a aprendizagem (ARROIO, 2006).

E se pudéssemos usar exemplos ainda mais comuns ao nosso dia a dia envolvendo cores para explicar conceitos químicos? Quem nunca ficou fascinado com os letreiros luminosos nas fachadas de lojas nas ruas e quis saber qual o motivo daquele fenômeno ou como montar um sistema daquele tipo?

Pois bem, a química também está ali e por meio de seu conhecimento podemos entender e controlar este tipo de aparato que desperta tanto interesse de todos. Trata-se da emissão de luz devido a um processo de excitação eletrônica, que pode ocorrer na forma de fluorescência, em que a emissão de luz cessa quando a fonte de energia é desligada, ou como fosforescência, que pode durar horas, mesmo depois de desligada a fonte de luz (NERY \& FERNANDEZ, 2004).

Esses fenômenos podem ser reproduzidos utilizando-se tubos de vidro contendo algum gás com baixa pressão e passando-se correntes elétricas através deles, por exemplo. Se o tubo for incolor e contiver gás neônio puro a baixa pressão, quando os elétrons são excitados devido à corrente elétrica, este emite luz de comprimento de onda relativo à cor vermelho-alaranjada (PEIXOTO, 1999). As cores ainda podem ser alteradas tanto pela mistura de gases, como por exemplo adicionando pequena pressão de hélio, argônio e materiais fluorescentes, quanto pelo uso de vidro colorido.

Deste modo, utilizando esses experimentos de lâmpadas coloridas torna-se possível explorar conceitos de estrutura atômica, transições eletrônicas, interação da radiação 
eletromagnética com a matéria, dentre outros, que muitas vezes são enfadonhos para os alunos quando vistos por meio de aulas puramente expositivas, mas que podem se tornar mais atraentes se for usado um exemplo do cotidiano e que tem o apelo visual.

\section{Considerações Finais}

Com base nas reflexões contidas neste trabalho, pudemos destacar que a cor tem grande relevância na química, na interação do homem com o meio no qual está inserido e também em sua capacidade de comunicação, por meio da construção visual e de inúmeras informações que a visão traz. Portanto o uso criativo de exemplos e experimentos envolvendo transformações químicas que ocorrem com mudança de coloração, bem como da investigação de sistemas químicos coloridos, pode contribuir para aumentar o interesse dos alunos no estudo da Química, sobretudo em assuntos que por muitas vezes são de difícil compreensão. Pensamos que isto é possível porque, ao estarmos mais interessados, mais atentos e com a imaginação estimulada, produzimos mais. O aprendizado pode ser lúdico, se realizar por meio de atividades que deem prazer, o que naturalmente ocorre quando entendemos melhor o ambiente ao nosso redor, aprender é estimulante. Foi discutido como a cor na química pode tornar o aprendizado mais interessante. Portanto, colorir é também aprender!

\section{Referências}

ARROIO, A.; HONÓRIO, K. M.; WEBER, K. C.; HOMEM-DE-MELLO, P.; GAMBARDELLA, M. T. P.; DA SILVA, A. B. F. O show da química: motivando o interesse científico. Química Nova, v. 29, n. 1, p.173-178, 2006.

DE CARVALHO, L. P.; REZENDE, H. C.; DA SILVA, R. M. G.; COELHO, N. M. M. Reações Oscilantes no Ensino de Química. In: Reunião Anual da Sociedade Brasileira de Química, 29a., 2006. Águas de Lindóia - SP. Anais... Águas de Lindóia, 2006. Disponível em http://sec.sbq.org.br/cd29ra/resumos/T1402-1.pdf. Acesso em: 30, set, 2017.

DENIS, C. Metodologia de seleção de tomates para processamento industrial por meio da visão computacional e redes neurais. 2009. 117f. Dissertação (Mestrado em Engenharia de Processos Químicos e Bioquímicos) - Centro Universitário do Instituto Mauá de Tecnologia, São Caetano do Sul, 2009.

KANASHIRO, M. A Cidade e os Sentidos: Sentir a Cidade. Desenvolvimento e Meio Ambiente, n. 7, p. 155-160, 2003. 
LONDERO, F. T. Estimativa de orientação com uma bússola visual baseada em cores. 2016. 80f. Dissertação (Mestrado em Ciências da Computação) - Universidade Federal de Santa Maria, Santa Maria - RS, 2016.

LORETO E. L. S.; SARTORI H. S. Simulação da visão das cores: decodificando a transdução quântica-elétrica. Caderno Brasileiro de Ensino de Física, v. 25, n. 2: p. 266-286, 2008. https://periodicos.ufsc.br/index.php/fisica/article/viewFile/2175$7941.2008 v 25 n 2 p 266 / 5635$

LUZZI, F. O. Óptica da fotografia: Abordagem CTS sob a perspectiva da Aprendizagem Significativa. 2017. 192f. Dissertação (Mestrado Profissional em Ensino de Ciências) - Universidade Federal de Ouro Preto, Ouro Preto - MG, 2017.

MARTINS, G. B. C.; SUCUPIRA, R. R.; SUAREZ, P. A. Z. A Química e as Cores. Revista Virtual de Química, v. 7, n. 4, p. 1508-1534, 2015.

NERY, A. L. P.; FERNANDEZ, C. Fluorescência e Estrutura Atômica: Experimentos Simples para Abordar o Tema. Química Nova na Escola, n. 19, p. 39-42, 2004.

NETO, J. D. M. Química da cor. In: Semana da Química do Departamento de Química da UFPR, XIV., 2007. UFPR. Anais... UFPR, 2007. Disponível em http://www.quimica.ufpr.br/quim/img/minicursos/Cores2007/Cor1.pdf. Acesso em: 30, set, 2017.

NISHIDA, S. M. Sentido da visão. Apostila do Curso de Fisiologia, Departamento de Fisiologia, Unesp-Botucatu, 2012. Disponível em: <http://www.ibb.unesp.br/Home/ Departamentos/Fisiologia/Neuro/08.sentido_visao.pdf>. Acesso em: 30, set, 2017.

PEIXOTO, E. M. A. Neônio. Química Nova na Escola, n. 9, 1999. Disponível em: <http://qnesc.sbq.org.br/online/qnesc09/elemento.pdf>. Acesso em: 30, set, 2017.

UFF. Espaço UFF de Ciências. Percepção do Ambiente. Disponível em http://www.uff.br/espacouffciencias/percepcaodoambiente.htm. Acesso em: 30, set, 2017. 